\title{
MicroRNA-15b suppresses the growth and invasion of glioma cells through targeted inhibition of cripto-1 expression
}

\author{
GUAN SUN $^{1 *}$, SHU-SHAN YAN ${ }^{2 *}$, LEI SHI $^{3 *}$, ZHENG-QIANG WAN $^{1}$, \\ NAN JIANG ${ }^{1}$, LIN-SHAN FU ${ }^{1}$, MIN LI $^{4}$ and JUN GUO ${ }^{1}$ \\ ${ }^{1}$ Department of Neurosurgery, Fourth Affiliated Hospital of Nantong University, First Hospital of Yancheng, Yancheng, \\ Jiangsu 224001; ${ }^{2}$ Department of Surgical Oncology, Eighty-First Hospital of People's Liberation Army, \\ Nanjing, Jiangsu 210002; ${ }^{3}$ Department of Neurosurgery, The First People's Hospital of Kunshan Affiliated \\ with Jiangsu University, Suzhou, Jiangsu 215300; ${ }^{4}$ Department of Neurosurgery, Jiangning Hospital \\ Affiliated with Nanjing Medical University, Nanjing, Jiangsu 211100, P.R. China
}

Received May 23, 2015; Accepted February 4, 2016

DOI: $10.3892 / \mathrm{mmr} .2016 .5126$

\begin{abstract}
Gliomas are the most common type of malignant brain tumor. Studies have identified that miR-15b is negatively correlated with cripto-1 expression in glioma cells, and these molecules serve an important role in cancer development and progression. The current study was undertaken to further examine the association between these two molecules. Fluorescent quantitative PCR confirmed that miR-15b expression was significantly downregulated in glioma tissue while cripto-1 expression was significantly increased. Subsequent to transfection with miR-15b mimics, cripto-1 expression was significantly suppressed, and dual luciferase reporter assays further demonstrated that miR-15b regulates cripto-1 in a targeted manner. Furthermore, miR-15b inhibited proliferation and invasion, and promoted apoptosis of glioma cells while downregulating the expression of MMP-2 and MMP-9. In contrast, cripto-1 expression had the opposite effects. Co-transfection with miR-15b mimics and the cripto-1 overexpression vector overcame the inhibitory action of miR-15b on cripto-1. Therefore, it is suggested that miR-15b modulates cell growth and invasion through targeted regulation of cripto-1 expression in glioma cells. This
\end{abstract}

Correspondence to: Dr Jun Guo, Department of Neurosurgery, Fourth Affiliated Hospital of Nantong University, First Hospital of Yancheng, 14 Yuehe Road, Tinghu, Yancheng, Jiangsu 224001, P.R. China

E-mail: junguo8916@163.com

Dr Min Li, Department of Neurosurgery, Jiangning Hospital Affiliated with Nanjing Medical University, 168 Dongshan Street Gushan Road, Nanjing, Jiangsu 211100, P.R. China

E-mail: sbn133@163.com

"Contributed equally

Key words: miR-15b, cripto-1, glioma, microRNA observation may provide novel targets for the prevention and treatment of gliomas.

\section{Introduction}

Gliomas are the most common type of malignancy in the brain, accounting for approximately $45-60 \%$ of brain tumors, and are characterized by high incidence, recurrence and mortality rates and a low curative rate (1). This neoplasm is a life-threatening disease of the nervous system. Therefore, it is of clinical importance to explore the underlying mechanisms, which may lead to the discovery of novel treatment modalities.

Cripto-1, otherwise known as teratocarcinoma-derived growth factor-1, is a member of the epidermal growth factor-cripto-1-FRL-1-cryptic protein family (2). Previous studies have demonstrated that cripto-1 is overexpressed in numerous types of cancer, however is under-expressed or absent in normal tissues (3-5). This fact suggests that an increase in the expression of cripto-1 may be an early event in the development of the associated types of cancer. An in vitro study demonstrated that overexpression of cripto-1 accelerated the growth of human breast cancer cells and promoted anti-apoptotic, -migratory and -invasive capabilities (6). An in-vivo study demonstrated that the growth of human nasopharyngeal carcinoma CNE-2 cells was significantly inhibited in cripto-1 knockout mice compared with the control group (7). Previous studies have demonstrated elevated cripto-1 expression in gliomas $(8,9)$. Pilgaard et al $(8)$ suggested that cripto-1 may be a prognostic biomarker for glioblastoma multiforme (GBM) with the potential of being a therapeutic target. Tysnes et al (9) observed that the majority of samples of patients with glioblastoma demonstrated significant levels of cripto-1, as it was detected by immunohistochemistry. Thus, numerous studies have demonstrated that cripto-1 may be a novel tumor-specific marker, and its value in early diagnosis of tumors, targeted treatment, drug resistance mechanisms and prognosis is of interest (3-9). However, further research is required to unravel the specific mechanisms of cripto- 1 in gliomas.

MicroRNAs (miRNAs) are a class of short, endogenous non-coding RNAs that function as post-transcriptional 
regulators (10). The miR-15 family is involved in the regulation of cellular functions, including apoptosis, cell cycle, differentiation and stress, and it is associated with a variety of human diseases, including cancer, cardiovascular and neurodegenerative diseases (11-13). The miR-15 family offers potential therapeutic targets. By miRNA expression profiling analysis, Xia et al (14) demonstrated that the expression of $\mathrm{miR}-15 \mathrm{~b} / 16$ was downregulated in a multi-drug-resistant gastric cancer cell line, SGC7901/VCR, compared with its non-resistant parent cell line, SGC7901, and that overexpression of miR-15b and miR-16 in the SGC7901/VCR cells enhanced the sensitivity of the cells to anticancer drugs, making them more susceptible to apoptosis. A previous study demonstrated that a lower expression level of miR-15b was associated with a shorter overall survival time, suggesting that miR-15b may be an intrinsic factor that serves an important role in the malignant progression of gliomas (15).

Prediction analysis indicated that miR-15b has binding sites on cripto-1. It is hence possible that miR-15b may suppress cancer by regulating cripto-1, thus cellular experiments were performed in the current study to test the above prediction.

\section{Materials and methods}

Clinical data and cell culture. A total of 30 glioma tissues, and matched adjacent noncancerous tissues, were harvested from patients at the Fourth Affiliated Hospital of Nantong University (Yancheng, China). All included cases were newly diagnosed, which were screened and verified by an experienced pathologist following surgical resection. Samples were harvested and analyzed with prior written informed consent from the patients between 2011 and 2014. The present study was approved by the Ethics Committee of the Fourth Affiliated Hospital of Nantong University, First Hospital of Yancheng. Human GBM8401 and GBM glioma cells (China Center for Type Culture Collection, Wuhan, China) and HEK293T cells (ATCC, Manassas, VA, USA) were cultured in Gibco Dulbecco's modified Eagle's medium (DMEM; Thermo Fisher Scientific, Inc., Waltham, MA, USA) supplemented with $10 \%$ heat-inactivated fetal calf serum (Thermo Fisher Scientific, Inc.). The cells were maintained at $37^{\circ} \mathrm{C}$ in an atmosphere of humidified air with $5 \% \mathrm{CO}_{2}$ in a cell culture incubator.

Over-expression vector construction and transfection. Total RNA of GBM8401 cells was extracted using TRIzol (Invitrogen; Thermo Fisher Scientific, Inc.). Reverse transcription-quantitative polymerase chain reaction (RT-qPCR) was used to amplify the cripto-1 coding region. It was then cloned into pcDNA3.1, using the Kpn I and EcoR I (Takara Biotechnology Co., Ltd., Dalian, China) restriction enzymes, sequenced and verified. The gene amplification primers are presented in Table I. The human miRNA (Hsa)-miR-15b and negative controls mimics were synthesized by Shanghai GenePharma Co., Ltd (Shanghai, China). GBM8401 cells were seeded into a 6 -well plate $\left(1 \times 10^{5}\right.$ cells $\left./ \mathrm{ml}\right)$ and incubated for $24 \mathrm{~h}$, and plasmid and miRNA transfection was conducted using Lipofectamine 2000 (Invitrogen; Thermo Fisher Scientific, Inc.), upon $70 \%$ confluency according to the manufacturer's instructions. The concentrations of the transfection plasmid and miRNA were $2 \mu \mathrm{g} / \mathrm{ml}$ and $50 \mathrm{nM} /$ well, and the DMEM medium was changed within 4-6 h subsequent to transfection. After $48 \mathrm{~h}$, the transfected cells were analyzed by RT-qPCR and western blotting.

Quantitative fluorescence PCR. Total RNA was extracted from the GBM8401 cells using TRIzol. For the detection of mature miRNA, a stem-loop RT-qPCR assay was conducted. Briefly, $1 \mu \mathrm{g}$ RNA and $1 \mu \mathrm{l}$ specific stem-loop RT primers $(10 \mu \mathrm{M})$ were incubated at $85^{\circ} \mathrm{C}$ for $5 \mathrm{~min}$, then held at $4^{\circ} \mathrm{C}$. A mixture of $4 \mu \mathrm{l} 5 \mathrm{X}$ buffer, $2 \mu \mathrm{l}$ dNTPs (10 mM), $0.5 \mu 1$ RNase inhibitor and $0.5 \mu \mathrm{l}$ Moloney murine leukemia virus (Promega Corporation, Madison, WI, USA) was added and incubated for $30 \mathrm{~min}$ at $16^{\circ} \mathrm{C}, 30 \mathrm{~min}$ at $42^{\circ} \mathrm{C}, 5 \mathrm{~min}$ at $85^{\circ} \mathrm{C}$ and then maintained at $4^{\circ} \mathrm{C}$. qPCR was performed using $10 \mu 12 \mathrm{X} \mathrm{SYBR}$ Green qPCR SuperMix (Invitrogen; Thermo Fisher Scientific, Inc.), with $5 \mu \mathrm{l}$ cDNA, $0.5 \mu \mathrm{l}$ forward primer, $0.5 \mu \mathrm{l}$ reverse primer and $4 \mu \mathrm{l}$ RNase-free $\mathrm{ddH}_{2} \mathrm{O}$ contained in $20 \mu \mathrm{l}$ reaction mixture. The reaction was performed with one cycle of $95^{\circ} \mathrm{C}$ for $5 \mathrm{~min}$ and $40 \mathrm{cycles}$ of $95^{\circ} \mathrm{C}$ for $15 \mathrm{sec}, 60^{\circ} \mathrm{C}$ for $15 \mathrm{sec}$ and $72^{\circ} \mathrm{C}$ for $35 \mathrm{sec}$ using the Applied Biosystems 7500 Real-Time PCR system (Thermo Fisher Scientific, Inc.). The U6 small nuclear RNA (U6 snRNA) was utilized as reference of the miRNA examination and the primers of mature miRNA were obtained from Thermo Fisher Scientific, Inc. Furthermore, oligo dT primers were used in reverse transcription. The primers used for the cripto-1 examination are demonstrated in Table I. The reaction was performed at one cycle of $95^{\circ} \mathrm{C}$ for $5 \mathrm{~min}$ and 40 cycles of $95^{\circ} \mathrm{C}$ for $30 \mathrm{sec}, 58^{\circ} \mathrm{C}$ for $30 \mathrm{sec}$ and $72^{\circ} \mathrm{C}$ for $30 \mathrm{sec}$. Three independent experiments were conducted for each sample. Data were normalized and fold changes were calculated using the $2^{-\Delta \Delta \mathrm{Cq}}$ normalization method (16).

Western blot analysis. The total cellular proteins were extracted from the GBM8401 cells by lysis buffer (Pierce Biotechnology, Inc., Rockford, IL, USA). The supernatant containing proteins was obtained following shaking at $4^{\circ} \mathrm{C}$ for $20 \mathrm{~min}$ and centrifugation at $10,000 \mathrm{x} \mathrm{g}$ at $4^{\circ} \mathrm{C}$ for $10 \mathrm{~min}$. The Bradford protein assay (Pierce Biotechnology, Inc.) was used to determine the protein concentrations. An equal quantity of proteins $(20 \mu \mathrm{g})$ was loaded onto $8 \%$ Tris-glycine sodium dodecyl sulfate-polyacrylimide gel electrophoresis gels (Bio-Rad Laboratories, Inc., Hercules, CA, USA) at $40 \mathrm{~V}$ for $5 \mathrm{~h}$ and the separated proteins were transferred onto nitrocellulose membranes (Pierce Biotechnology, Inc.). Membranes were then blocked in 5\% non-fat milk in Tris-buffered saline with Tween-20 (TBST; Pierce Biotechnology, Inc.) for $1 \mathrm{~h}$ at $4^{\circ} \mathrm{C}$. Subsequent to blocking, membranes were incubated with cripto-1 (1:400; NB100-1598; Novus Biologicals, LLC, Littleton, CO, USA), matrix metalloproteinase (MMP)-2 (1:800; 4022), MMP-9 (1:800; 2270) polyclonal rabbit antibodies and glyceraldehyde 3-phosphate dehydrogenase (1:1,000; 3683; all Cell Signaling Technology Inc., Danvers, MA, USA) monoclonal rabbit antibody overnight at $4^{\circ} \mathrm{C}$. Monoclonal anti-rabbit immunoglobulin $\mathrm{G}$ antibody conjugated with horseradish peroxidase (7074; Cell Signaling Technology Inc.) at 1:7,000 dilution was added to the membranes and incubated for $1 \mathrm{~h}$ at $37^{\circ} \mathrm{C}$. TBST was used for washing the membranes every $10 \mathrm{~min}$, for a total of $30 \mathrm{~min}$. Protein bands were detected using the West Femto system (Pierce Biotechnology, Inc.). The light-emitting films were scanned by a GelBlot-Pro 1.01 gel imaging system (UVP, LLC, Upland, CA, USA) and the gray 
Table I. Primer sequences.

Technique/gene

Primer sequence $\left(5^{\prime}->3\right.$ ')

Size (bp)

Cripto-1 CDS amplification

S: GGGGTACCGCCACCATGGACTGCAGGAAGATGGC

Cripto-1 3'UTR amplification

A: CGGAATTCTTAATAGTAGCTTTGTATAGAAAGGCA

S: CCGCTCGAGTCGACATTGACCTATTTCCAG

A: ATAAGAATGCGGCCGCGGTCAATATAGTTTCCATTTTTACTG

Quantitative PCR

GAPDH

S: GGTATCGTGGAAGGACTC

A: GTAGAGGCAGGGATGATG

Cripto-1

S: AATTTGCTCGTCCATCTC

bp, base pairs; CDS, coding sequence; S, sense; A, antisense; UTR, untranslated region; PCR, polymerase chain reaction GAPDH, glyceraldehyde 3-phosphate dehydrogenase. The underlined region indicates the restriction enzyme cutting site.

values of band were measured with the Gel-Pro Analyzer 6.3 software (Media Cybernetics, Inc., Rockville, MD, USA).

Dual luciferase assay. The cripto-1 3' untranslated region (UTR) was amplified from cDNA (Table I) and cloned into the psiCHECK-2 vector (Promega Corporation). The QuikChange II Site-Directed Mutagenesis kit (Stratagene; Agilent Technologies, Inc., Santa Clara, CA, USA) was used to generate the mutant-type cripto-1 3'UTR in which the seven mutated nucleotides were underlined within the seed region of the miR-15b binding site. Reporter vector psiCHECK-2 carrying the 3'UTR sequences of cripto-1 was assayed for luciferase expression using the Dual Glo Luciferase Assay System (Promega Corporation) according to the manufacturer's instructions. The experiment was performed in duplicate in three independent experiments.

Cell proliferation assay. Cell proliferation was detected in 96-well plates using a colorimetric immunoassay, based on the measurement of 5-bromo-2'-deoxyuridine (BrdU) incorporation during the DNA synthesis (BrdU ELISA kit, Roche Diagnostics $\mathrm{GmbH}$, Mannheim, Germany). Subsequent to 48-h transfection, the medium was removed and GBM8401 and GBM cells were incubated with BrdU (10 mM; Roche Diagnostics $\mathrm{GmbH}$ ) for $3 \mathrm{~h}$ at $37^{\circ} \mathrm{C}$. Cells were fixed with $4 \%$ paraformaldehyde (Sigma-Aldrich, St. Louis, MO, USA), and incubated with the peroxidase-conjugated sheep anti-BrdU polyclonal antibody $(1: 1,000 ; 11647229001$; Roche Diagnostics GmbH) for $90 \mathrm{~min}$ at room temperature. The peroxidase substrate 3,3',5,5'-tetramethylbenzidine (Roche Diagnostics $\mathrm{GmbH}$ ) was then added to the cells and BrdU incorporation was quantitated by differences in absorbance at wavelength 370-492 nm. Cell proliferation was expressed as the mean percentage of the control values (set at $100 \%$ ).

Flow cytometric analysis. Subsequent to transfection with plasmid and miRNA, the GBM8401 cells were washed with phosphate-buffered saline (PBS; Pierce Biotechnology, Inc.) and fixed in $75 \%$ ethanol overnight at $-20^{\circ} \mathrm{C}$. The fixed cells were stained with propidium iodide (PI) solution $(1.21 \mathrm{mg} / \mathrm{ml}$ Tris, $700 \mathrm{U} / \mathrm{ml}$ RNase, $50.1 \mu \mathrm{g} / \mathrm{ml}$ PI, pH 8.0; Sigma-Aldrich) for $4 \mathrm{~h}$ in the dark. Red PI fluorescence was measured with the
Epics XL flow cytometer using CXP 2.2 software (Beckman Coulter, Inc., Brea, CA, USA). In each sample, 10,000 events were measured for apoptosis detection and cell cycle analysis. Data were analyzed with the Expo32 analysis tool (Beckman Coulter, Inc.). The DNA histogram was represented by the proportion of cells in the $\mathrm{G}_{0} / \mathrm{G}_{1}, \mathrm{~S}$ and $\mathrm{G}_{2} / \mathrm{M}$ phases. Apoptotic cells with hypodiploid DNA content were measured by quantifying the sub- $\mathrm{G}_{1}$ peak in the cell cycle pattern.

Transwell matrigel invasion assay. Invasion of cells was assessed with the Transwell matrigel invasion assay (BD Biosciences, San Jose, CA, USA). Briefly, $200 \mu$ l of transfected GBM8401 cells $\left(1 \times 10^{6}\right.$ cells $\left./ \mathrm{ml}\right)$ and $600 \mu 1$ of the complete medium were added to the upper and lower compartments of the chamber, respectively. Subsequent to 48 -h incubation, cells migrating to the lower side of the filter were fixed with $4 \%$ paraformaldehyde for $15 \mathrm{~min}$ at room temperature, washed with PBS, stained with crystal violet (Sigma-Aldrich) and then observed under the CKX41 inverted microscope (Olympus Corporation, Tokyo, Japan).

Statistical analysis. The experiments were conducted a minimum of 3 times and results are expressed as the mean \pm standard deviation. The SPSS statistical package (SPSS software, version 17.0 for Windows; SPSS, Inc. Chicago, IL, USA) was used for statistical analysis. Differences between the control and treated groups were analyzed using non-parametric statistical analysis (Mann-Whitney $\mathrm{U}$ test). $\mathrm{P}<0.01$ was considered to indicate a statistically significant difference.

\section{Results}

miR-15b downregulates cripto-1 expression in glioma cells. The expression levels of miR-15b and cripto- 1 from the collected clinical samples were examined to investigate the association of miR-15b and cripto- 1 in gliomas. The results demonstrated that the mRNA expression levels of miR-15b were downregulated in glioma tissues whereas cripto-1 expression was significantly increased, suggesting a negative correlation between the two molecules (Fig. 1A and B). The addition of miR-15b mimics led to significantly reduced cripto-1 expression 
A

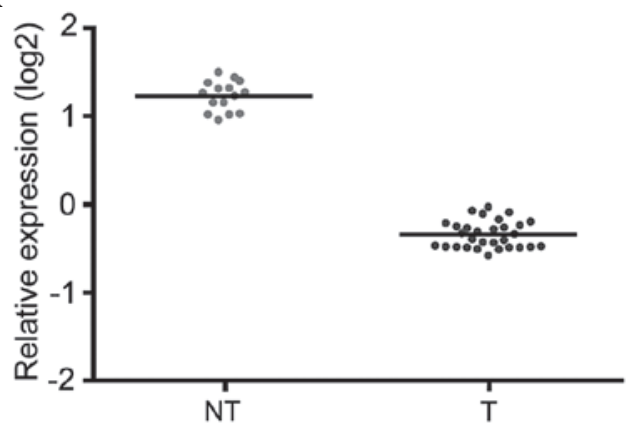

C

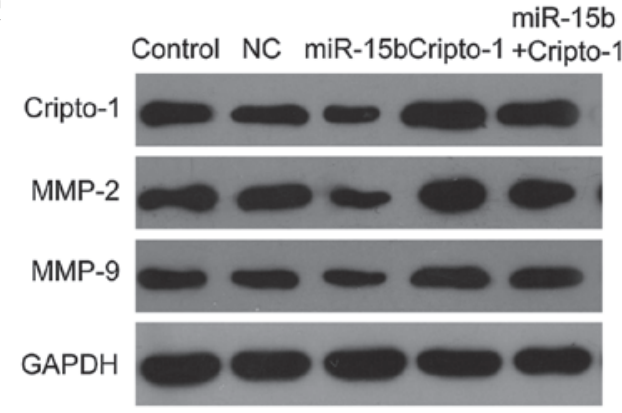

B

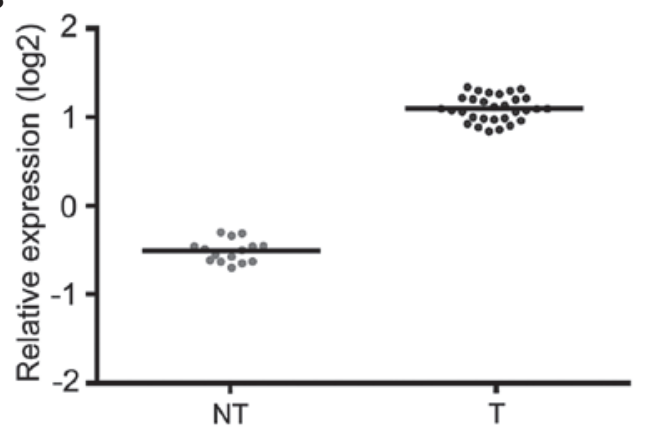

D

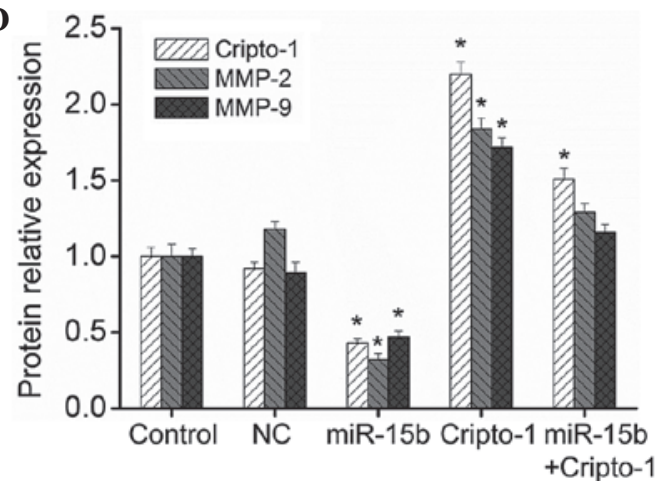

Figure 1. miR-15b and cripto-1 mRNA and protein expression levels in patients with glioma and GBM8401 cells. Reverse transcription-quantitative polymerase chain reaction analysis demonstrated (A) downregulation of the miR-15b mRNA expression levels and (B) upregulation of the cripto-1 expression in patients with glioma $(\mathrm{P}<0.01$ vs. NT). (C) Cripto-1 protein expression levels in the GBM8401 cells following transfection with miRNA mimics and/or cripto-1-pcDNA3.1. (D) Quantification of results. Data are presented the mean \pm standard deviation ( $\mathrm{n}=3$ ). " $\mathrm{P}<0.01$ vs. control. NT, non-tumor; T, tumor; NC, negative control, miR, microRNA, MMP, matrix metalloproteinase; GAPDH, glyceraldehyde 3-phosphate dehydrogenase.

hsa-miR-15b: $\quad 3^{\prime}$ acauUUGGU-ACUAC -- ACGACGAu 5' $:||||$ | | | | |||||||

Cripto-1 wt 3' UTR: 5' ucauGACCAGUAAAGGCUGCUGCUa 3'

Cripto-1 mu 3' UTR: 5' ucauGACCAGUAAAGGCAUGACUGa 3'
B

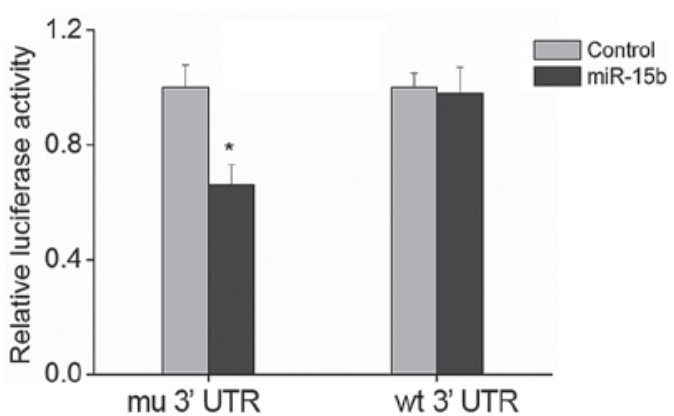

Figure 2. Prediction of the miR-15b targeting gene. (A) miR-15b target sites in the conservative sequence of cripto-1 3'UTR. (B) The luciferase expression level of human embryonic kidney-293 cells transfected with cloning cripto-1 3'UTR vector or mutant cripto-1 3'UTR vector and miR-15b mimics. Data are presented as the mean \pm standard deviation $(\mathrm{n}=3)$. ${ }^{*} \mathrm{P}<0.01$ vs. the control group. hsa-miR, human microRNA; UTR, untranslated region; mu, mutant; wt, wild type.

in glioma cells (Fig. 1C and D). Although cripto-1 expression was still upregulated compared with the control subsequent to co-transfection with miR-15b mimics and cripto-1 overexpression vector, its level was significantly lower than in cells transfected with the cripto-1 overexpression vector alone (Fig. 1C and D), indicating that miR-15b can inhibit cripto-1 expression in glioma cells.

miR-15b regulates cripto-1 in a targeted manner. Prediction by biological software demonstrated that miR-15b has binding sites on cripto-1 (Fig. 2A). The dual luciferase reporter gene assay was performed to test this prediction. The 3' UTR of cripto-1 gene was cloned into psiCHECK-2, a dual luciferase reporter vector, and the target sites of miR-15b were mutated
(Fig. 2A). The two plasmids were then transfected together with the miR-15b mimics into human embryonic kidney-293T cells and the alterations in the luciferase expression were analyzed. Luciferase expression in the cells transfected with plasmids containing $3^{\prime}$ UTR of cripto-1 was significantly reduced by approximately $35 \%$ compared with the cells transfected with the empty reporter vector (Fig. 2B; $\mathrm{P}<0.01$ ). Furthermore, no significant alterations were observed in the luciferase expression in the cells transfected with plasmids containing the mutant 3' UTR of cripto-1 (Fig. 2B; P>0.05). This demonstrated that miR-15b specifically binds to the 3' UTR of cripto-1 gene, suggesting that cripto-1 is a target gene of miR-15b. Therefore, miR-15b may have an anti-tumor role by regulating cripto-1. 
A

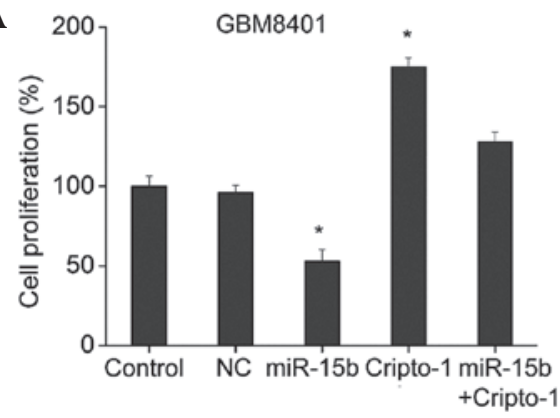

B

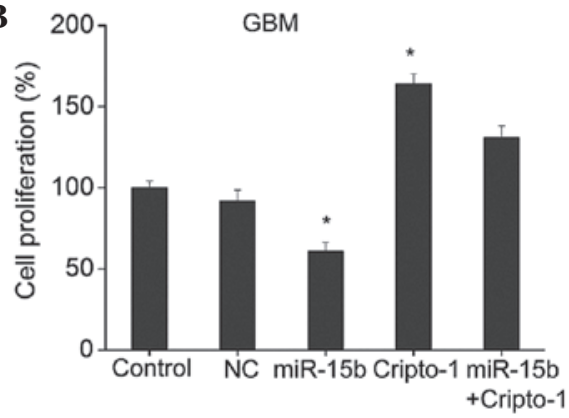

Figure 3. Effects of miR-15b overexpression on the glioma cell proliferation. (A) GBM8401 and (B) GBM cells were transfected with miR-15b and/or the cripto-1-overexpressing vector, and the cell proliferation was assessed using the 5-bromo-2'-deoxyuridine assay. Data are presented as the mean \pm standard deviation ( $\mathrm{n}=3$ ). ${ }^{*} \mathrm{P}<0.01$ vs. the control group. GBM, glioblastoma multiforme; $\mathrm{NC}$, negative control; miR, microRNA.
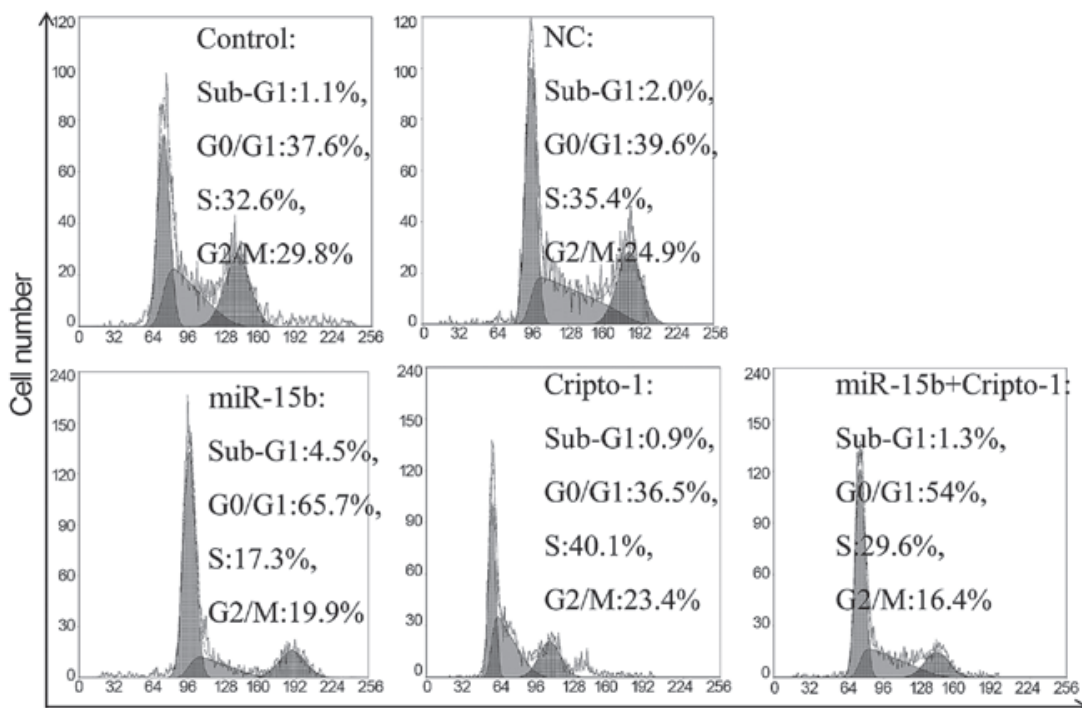

DNA content

Figure 4. Examination of glioma cell apoptosis using flow cytometric analysis. Graphs are representative of three independent experiments with similar results. NC, negative control; miR, microRNA.

miR-15b inhibits glioma cell proliferation through targeted regulation of cripto-1. As demonstrated in Fig. 3, the cell proliferation assays with BrdU detection following transfection with the miR-15b mimics indicated that miR-15b significantly inhibited the proliferation of the GBM8401 and GBM cells compared with the control group (Fig. 3; P<0.01). Transfection with the cripto-1 overexpression vector resulted in significantly increased cripto-1 expression and enhanced proliferation of the GBM8401 and GBM cells compared with the control group (Fig. 3; P<0.01). In addition, cell proliferation was significantly increased in the cells co-transfected with the miR- $15 \mathrm{~b}$ mimics and cripto-1 overexpression vector, compared with the cells transfected with the cripto- 1 overexpression vector alone (Fig. 3). Furthermore, cells transfected with the miR-15b mimics alone had significantly lower proliferation compared with the other three groups (Fig. 3). The results suggested that miR-15b and cripto-1 have opposite roles in the glioma cell proliferation, and that miR-15b may suppress glioma cell proliferation by regulating the expression of cripto-1.

miR-15b promotes apoptosis of glioma cells through targeted regulation of cripto-1.Further tests on the cell cycle demonstrated that the proportion of sub- $\mathrm{G}_{1}$ peak markedly increased in the cells transfected with the miR-15b mimics and the cell cycle was arrested in the $G_{0} / G_{1}$ phase (Fig. 4), which further demonstrates that miR-15b promotes apoptosis of glioma cells. Western blot results (Fig. 1C and D) demonstrated that the degree of apoptosis was negatively correlated with the expression levels of cripto-1. The pro-apoptotic effect of miR-15b was inhibited by sustained cripto-1 expression in the cells co-transfected with miR-15b and cripto-1, compared with the control group. Cripto-1 expression was significantly reduced in the cells transfected with miR-15b mimics alone, which resulted in significantly increased apoptosis. These results demonstrated that miR-15b promoted apoptosis by inhibiting the cripto-1 expression.

miR-15b inhibits migration of glioma cells through targeted regulation of cripto-1. Glioma cells have invasive and metastatic abilities (17), and cripto-1 was demonstrated to promote cell invasion and metastasis. Therefore, the effects of the miR-15b on the invasion and metastasis of glioma cells were further investigated. Results from the Transwell assay demonstrated that miR-15b significantly inhibited the invasion of glioma cells and cripto-1 increased the invasiveness of 
A

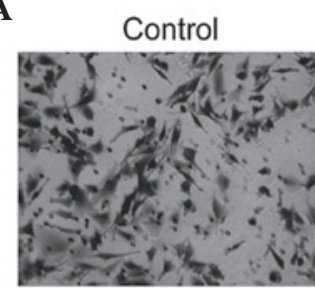

Cripto-1

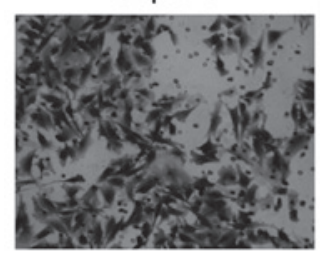

NC

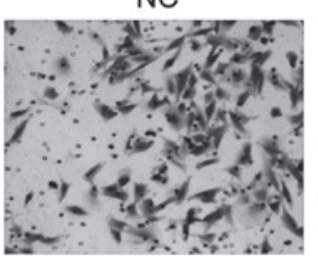

miR-15b+Cripto-1

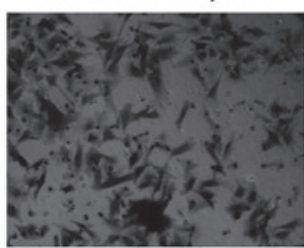

miR-15b

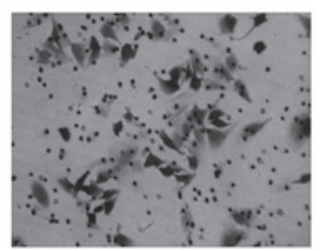

B

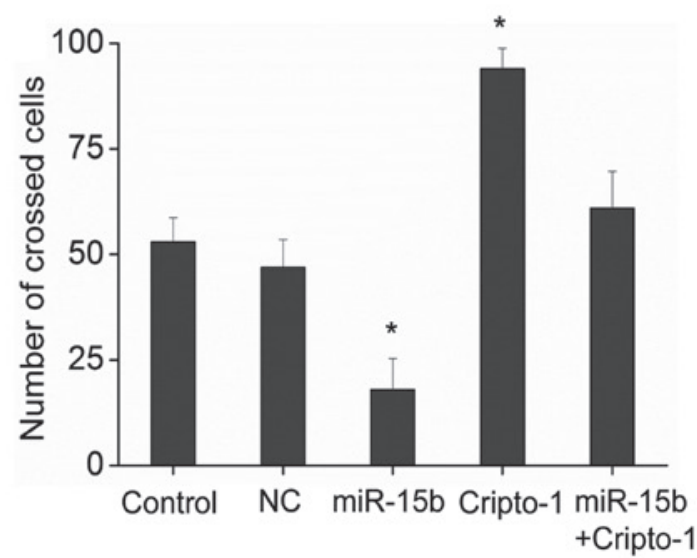

Figure 5. (A) Effects of miR-15b on invasion of glioma cells. (B) Quantitative analysis of the anti-invasive effects of miR-15b. Data are presented as the mean \pm standard deviation $(\mathrm{n}=3)$. ${ }^{*} \mathrm{P}<0.01$ vs. the control group. $\mathrm{NC}$, negative control; miR, microRNA.

glioma cells compared with the control group (Fig. 5; $\mathrm{P}<0.01$ ). Furthermore, no significant difference was demonstrated in the ability of cell invasion among cells co-transfected with the miR-15b and cripto-1, and the control cells. The invasion and metastatic abilities are associated with the expression of MMPs, of which MMP-2 and -9 are two major members. Western blot analysis demonstrated that miR-15b significantly reduced the expression of MMP-2 and -9, and cripto-1 promoted the expression of MMP-2 and -9 (Fig. 1C and D). In cells co-transfected with miR-15b and cripto-1, the expression of MMP-2 and -9 remained upregulated, but significantly reduced relative to cells transfected with the cripto-1 overexpression vector alone. These results demonstrated that miR-15b modulates the invasive ability of glioma cells by regulating the expression of cripto-1, subsequently reducing the expression of MMP-2 and -9 .

\section{Discussion}

The etiology, mechanisms, diagnosis and treatment of gliomas have been previously investigated, however their origin remains undefined and the clinical progress is slow $(18,19)$. Therefore, the search for the molecular mechanisms underlying the pathological process of gliomas has emerged as a focus for research, to aid in the diagnosis and treatment of gliomas.

Previous in-vivo and in-vitro studies have demonstrated the oncogenic role of human cripto-1 $(20,21)$, however, the role of cripto-1 in gliomas is unclear. The present study demonstrated that cripto-1 expression was significantly increased in glioma tissue, which is consistent with the results of Pilgaard et al (8) and Tysnes et al (9). In addition, the present study demonstrated that cripto-1 promoted the proliferation and inhibited the apoptosis of glioma cells. Strizzi et al (3) demonstrated that inhibition of the cripto-1 expression in colon cancer cells suppressed their growth and tumorigenesis potential in soft agar. In another study, the use of cripto-1 blocking antibody suppressed the cripto-nodal signaling system and inhibited tumor growth by $70 \%$ in in-vivo models of testicular and colon cancer (22). Therefore, cripto-1 has a similar growth-promoting and neoplastic role in gliomas as in other types of cancer.
In the present study, the results of the cell invasion assays demonstrated that cripto-1 promoted the invasion of glioma cells and enhance the expression of MMP-2 and -9. Wu et al (7) demonstrated that the use of lentivirus-mediated small interfering RNA inhibited cripto-1 expression in nasopharyngeal carcinoma cell lines, suppressed cell growth, and significantly reduced the invasion potential of nasopharyngeal carcinoma cell lines. Strizzi et al (23) demonstrated that cripto-1 promoted invasion and metastasis by regulating epithelial-mesenchymal transition in mouse mammary epithelial cells cultured in-vitro and mouse mammary tumor cells grown in-vivo. Normanno et al (6) indicated that MCF-7 breast cancer cells with increased expression of teratocarcinoma-derived growth factor 1 exhibited significantly improved apoptosis resistance, growth and proliferation capabilities, and invasion and migration potential in-vitro. These results are consistent with the observations of the current study, supporting the oncogenic role of cripto-1.

Numerous studies have demonstrated that miRNAs serve an important role in regulating numerous physiological and pathological processes. Abnormally increased onco-miRNA expression and abnormally reduced tumor suppressor miRNA expression are associated with the development and progression of a variety of types of cancer $(24,25)$. The present study confirmed that miR-15b was downregulated in glioma tissue, which is consistent with previous observations (15). In addition, previous studies demonstrated that certain miR-15 family members are downregulated in patients with chronic lymphocytic leukemia, glioma and prostate cancer (11-13), suggesting that the miR-15 family represents an important class of tumor suppressors.

The present study demonstrated that the miR-15b expression was negatively correlated with the cripto-1 expression in glioma tissue, suggesting an association between the two molecules. The results of the biological software analysis indicated that miR-15b has binding sites on cripto-1, thus miR-15b may regulate cripto-1 in a targeted manner. miR-15b significantly inhibited cripto-1 expression in glioma cells following transfection with the miR-15b mimics, and dual luciferase reporter assays demonstrated that miR-15b directly targets cripto-1. Additional tests indicated that miR-15b inhibits the proliferation and invasion of glioma cells while promoting apoptosis, by inhibiting the expression of 
MMP-2 and -9. Co-transfection with miR-15b and cripto-1 overcame the action of miR-15b, however its effect in invasion was significantly attenuated compared with the cells transfected with cripto-1 overexpression vector alone. This further indicated that miR-15b modulates the growth and invasion of glioma cells by regulating cripto-1. A previous study demonstrated that overexpression of miR-15b inhibited proliferation by arresting cell cycle progression and inducing apoptosis, possibly by directly targeting cyclin D1 in glioma cells (26). Xia et al (27) demonstrated that overexpression of miR-15b resulted in cell cycle arrest at $G_{0} / G_{1}$ phase, and suppression of miR-15b expression resulted in a reduction of cell populations in $G_{0} / G_{1}$ and a corresponding increase of cell populations in the $S$ phase. Zheng et al (28) demonstrated that miR-15b and miR-152 reduced glioma cell invasion and angiogenesis via neuropilin 2 and MMP-3. Furthermore, Wu et al (29) demonstrated that downregulation of microRNA-15b by the hepatitis B virus $\mathrm{X}$ enhanced hepatocellular carcinoma proliferation via fucosyltransferase 2-induced Globo $\mathrm{H}$ expression. These results indicate that miR-15b affects the growth of tumor cells by regulating the expression of a series of genes.

In conclusion, the miR-15b expression is negatively associated with the cripto- 1 expression in glioma cells. miR-15b may subsequently impair growth and invasion of glioma cells through targeted regulation of cripto-1. This discovery may provide novel targets for the prevention and treatment of gliomas.

\section{Acknowledgements}

The current study was supported by the China Natural Science Foundation (grant nos. 81201976 and 81000963), Jiangsu Province's Natural Science Foundation (grant nos. BK2012670 and BK20141256), Jiangsu Province's Health Department (grant no. z201318) and Yancheng Medical Science Development Foundation (grant nos. YK2013003 and YK2013019).

\section{References}

1. Germano I, Swiss V and Casaccia P: Primary brain tumors, neural stem cell, and brain tumor cancer cells: Where is the link? Neuropharmacology 58: 903-910, 2010.

2. Bianco C, Strizzi L, Normanno N, Khan N and Salomon DS: Cripto-1: An oncofetal gene with many faces. Curr Top Dev Biol 67: 85-133, 2005.

3. Strizzi L, Bianco C, Normanno N and Salomon D: Cripto-1: A multifunctional modulator during embryogenesis and oncogenesis. Oncogene 24: 5731-5741, 2005.

4. De Luca A, Lamura L, Strizzi L, Roma C, D'Antonio A, Margaryan N, Pirozzi G, Hsu MY, Botti G, Mari E, et al: Expression and functional role of CRIPTO-1 in cutaneous melanoma. Br J Cancer 105: 1030-1038, 2011.

5. Yoon HJ, Hong JS, Shin WJ, Lee YJ, Hong KO, Lee JI, Hong SP and Hong SD: The role of Cripto-1 in the tumorigenesis and progression of oral squamous cell carcinoma. Oral Oncol 47: $1023-1031,2011$.

6. Normanno N, De Luca A, Bianco C, Maiello MR, Carriero MV, Rehman A, Wechselberger C, Arra C, Strizzi L, Sanicola M, et al: Cripto-1 overexpression leads to enhanced invasiveness and resistance to anoikis in human MCF-7 breast cancer cells. J Cell Physiol 198: 31-39, 2004.

7. Wu Z, Li G, Wu L, Weng D, Li X and Yao K: Cripto-1 overexpression is involved in the tumorigenesis of nasopharyngeal carcinoma. BMC Cancer 9: 315, 2009.

8. Pilgaard L, Mortensen JH, Henriksen M, Olesen P, Sørensen P, Laursen R, Vyberg M, Agger R, Zachar V, Moos T, et al: Cripto-1 expression in glioblastoma multiforme. Brain Pathol 24: 360-370, 2014.
9. Tysnes BB, Satran HA, Mork SJ, Margaryan NV, Eide GE, Petersen K, Strizzi L and Hendrix MJ: Age-dependent association between protein expression of the embryonic stem cell marker cripto-1 and survival of glioblastoma patients. Transl Oncol 6: 732-741, 2013.

10. Bartel DP: MicroRNAs: Target recognition and regulatory functions. Cell 136: 215-233, 2009.

11. Cimmino A, Calin GA, Fabbri M, Iorio MV, Ferracin M, Shimizu M, Wojcik SE, Aqeilan RI, Zupo S, Dono M, et al: miR-15 and miR-16 induce apoptosis by targeting BCL2. Proc Natl Acad Sci USA 102: 13944-13949, 2005.

12. Bonci D, Coppola V, Musumeci M, Addario A, Giuffrida R, Memeo L, D'Urso L, Pagliuca A, Biffoni M, Labbaye C, et al: The miR-15a-miR-16-1 cluster controls prostate cancer by targeting multiple oncogenic activities. Nat Med 14: 1271-1277, 2008.

13. Baraniskin A, Kuhnhenn J, Schlegel U, Maghnouj A, Zöllner H, Schmiegel W, Hahn S and Schroers R: Identification of microRNAs in the cerebrospinal fluid as biomarker for the diagnosis of glioma. Neuro-oncol 14: 29-33, 2012.

14. Xia L, Zhang D, Du R, Pan Y, Zhao L, Sun S, Hong L, Liu J and Fan D: miR-15b and miR-16 modulate multidrug resistance by targeting BCL2 in human gastric cancer cells. Int J Cancer 123: 372-379, 2008

15. Sun G, Yan S, Shi L, Wan Z, Jiang N, Li M and Guo J: Decreased expression of miR-15b in human gliomas is associated with poor prognosis. Cancer Biother Radiopharm 30: 169-173, 2015.

16. Livak KJ and Schmittgen TD: Analysis of relative gene expression data using real-time quantitative PCR and the 2(-Delta Delta C(T)) Method. Methods 25: 402-408, 2001.

17. Giese A, Bjerkvig R, Berens ME and Westphal M: Cost of migration: Invasion of malignant gliomas and implications for treatment. J Clin Oncol 21: 1624-1636, 2003.

18. Furnari FB, Fenton T, Bachoo RM, Mukasa A, Stommel JM, Stegh A, Hahn WC, Ligon KL, Louis DN, Brennan C, et al: Malignant astrocytic glioma: Genetics, biology, and paths to treatment. Genes Dev 21: 2683-2710, 2007.

19. Van Meir EG, Hadjipanayis CG, Norden AD, Shu HK, Wen PY and Olson JJ: Exciting new advances in neuro-oncology: The avenue to a cure for malignant glioma. CA Cancer J Clin 60: 166-193, 2010.

20. Zhong XY, Zhang LH, Jia SQ, Shi T, Niu ZJ, Du H, Zhang GG, Hu Y, Lu AP, Li JY, et al: Positive association of up-regulated Cripto-1 and down-regulated E-cadherin with tumour progression and poor prognosis in gastric cancer. Histopathology 52: 560-568, 2008.

21. Gong YP, Yarrow PM, Carmalt HL, Kwun SY, Kennedy CW, Lin BP, Xing PX and Gillett DJ: Overexpression of Cripto and its prognostic significance in breast cancer: A study with long-term survival. Eur J Surg Oncol 33: 438-443, 2007.

22. Adkins HB, Bianco C, Schiffer SG, Rayhorn P, Zafari M, Cheung AE, Orozco O, Olson D, De Luca A, Chen LL, et al: Antibody blockade of the Cripto CFC domain suppresses tumor cell growth in vivo. J Clin Invest 112: 575-587, 2003.

23. Strizzi L, Bianco C, Normanno N, Seno M, Wechselberger C, Wallace-Jones B, Khan NI, Hirota M, Sun Y, Sanicola M, et al: Epithelial mesenchymal transition is a characteristic of hyperplasias and tumors in mammary gland from MMTV-Cripto-1 transgenic mice. J Cell Physiol 201: 266-276, 2004.

24. Lee YS and Dutta A: MicroRNAs in cancer. Annu Rey Pathol 4: 199-227, 2009.

25. Schwarzenbach H, Nishida N, Calin GA and Pantel K: Clinical relevance of circulating cell-free microRNAs in cancer. Nat Rev Clin Oncol 11: 145-156, 2014.

26. Sun G, Shi L, Yan S, Wan Z, Jiang N, Fu L, Li M and Guo J: MiR-15b targets cyclin D1 to regulate proliferation and apoptosis in glioma cells. BioMed Res Int 2014: 687826, 2014.

27. Xia H, Qi Y, Ng SS, Chen X, Chen S, Fang M, Li D, Zhao Y, Ge R, Li G, et al: MicroRNA-15b regulates cell cycle progression by targeting cyclins in glioma cells. Biochem Biophys Res Commun 380: 205-210, 2009.

28. Zheng X, Chopp M, Lu Y, Buller B and Jiang F: MiR-15b and miR-152 reduce glioma cell invasion and angiogenesis via NRP-2 and MMP-3. Cancer Lett 329: 146-154, 2013.

29. Wu CS, Yen CJ, Chou RH, Chen JN, Huang WC, Wu CY and Yu YL: Downregulation of microRNA-15b by hepatitis B virus $\mathrm{X}$ enhances hepatocellular carcinoma proliferation via fucosyltransferase 2-induced Globo $\mathrm{H}$ expression. Int J Cancer 134: 1638-1647, 2014. 